\title{
Isolation and Antibiotics Susceptibility Profile of Staphylococcus aureus Isolated from Poultry Meat and Associated Environment in and around Junagadh District, Gujarat, India
}

\author{
K. R. Bhedi ${ }^{1 *}$, S. H. Sindhi ${ }^{1}$, J. B. Kathiriya ${ }^{1}$, B. S. Mathapati ${ }^{2}$ and A. R. Bariya ${ }^{3}$ \\ ${ }^{1}$ Department of Veterinary Public Health and Epidemiology, ${ }^{2}$ Department of Veterinary \\ Microbiology, ${ }^{3}$ Department of Livestock Products Technology, College of Veterinary Science \\ and Animal Husbandry, Junagadh Agricultural University, \\ Junagadh-362001, Gujarat, India \\ *Corresponding author
}

\section{A B S T R A C T}

Keywords

S. aureus, Poultry meat, Antimicrobial susceptibility

Article Info

Accepted:

07 September 2019

Available Online:

10 October 2019
The present study was undertaken to investigate the ecological studies of $S$. aureus isolates from poultry meat and associated environment in and around Junagadh District. A total of 200 Poultry meat and associated environment samples which comprised of Tracheal swabs $(n=40)$, Cloacal swabs $(n=40)$, Skin swabs $(n=40)$, Meat $(n=40)$ and environment sample (knife samples $(n=20)$ and butcher's hand swabs $(n=20)$ were collected from different retail poultry meat shops located in and around Junagadh district. Out of 200 samples, 27 isolates of $S$. aureus were found positive for $S$. aureus by culture and these isolates were further confirmed by biochemical test. The obtained $S$. aureus isolates were subjected to antibiotic sensitivity test. The isolates were found highly resistant to the Ampicillin (70.37\%) followed by Tetracycline (62.96\%) Co-Trimoxazole (33.33\%), Methicillin (25.92\%), Chloramphenicol $(22.22 \%)$ and Vancomycin $(18.51 \%)$ in their decreasing order. This study confirmed the presence of $S$. aureus, especially antibiotic-resistant strains in poultry meat.

\section{Introduction}

Throughout the Worldwide, millions of people were suffering from communicable and non communicable diseases caused by contaminated food. These diseases cause heavy toll in human life and suffering, particularly among infants, children, elderly and other susceptible persons. (van der vanter, 1999). Nowadays foods borne disease are of 
global public health concern and they are causing wide variety of illness and sometime even cause mortality in human beings. The survival of spores through the cooking process, germination, proliferation and production of toxins in food are responsible for human food borne diseases and source of the causative microorganisms (Senait and Moorty, 2016).

Food borne diseases are one of the major causes of concern in developing countries resulting in several deaths annually along with billions of dollars of economic burden. According to World Health Organization (WHO), approximately 600 million people are getting infected and around 420,000 die annually worldwide due to food borne pathogens. Most cases of food born outbreak are caused by Salmonella, Campylobacter, Escherichia coli, Listeria, Vibrio cholera and Staphylococcus aureus had been reported worldwide (Who, 2015; Herve and Kumar, 2017).

From last few decades poultry is a major fastest growing source of meat in world. (Kearney, 2010; Islam et al., 2014) Now there is upward trend in production and consumption of poultry meat and consumer expect safe and hygienic product without contamination with pathogenic microorganisms (Islam et al., 2014).

Poultry also act as important source and vehicle for transmission of food borne pathogen. At the time of slaughtering of poultry birds, there may be cross contamination of carcass with fecal and gut contain which may passed on as contaminants (Moustafa et al.,2016).

Staphylococcus aureus is one of the most important pathogenic bacteria due to its ability to cause food-borne diseases and various types of infections in human and animals (Świda et al., 2016). It is a Gram-positive bacterium that can be commonly found on the skin or in the nasal passages of most humans and animals (Jackson et al., 2013). It's widespread in the environment and often detected in air, dust, water, raw meat, other foods, and on environmental surfaces. It also produces heatstable enterotoxins during growth on a variety of foods, including meat and poultry products, eggs, cream-filled pastries, potatoes, and some salads. It survives desiccation and tolerates high levels of salt too. So it has become food safety concern for meat producers and food processors (Cunha et al., 2006; Owuna et al., 2015).

The presence of $S$. aureus in meat is often attributed to inadequate hygiene during handling by the individuals involved in the production of meat (Moustafa et al., 2016).

The presence of $S$. aureus in poultry meat posses a potential health hazard to consumers and the identification of such strains should be used as a part of risk analysis of meat and poultry products (Owuna et al., 2015).

Therefore, the present study aims to isolate, characterize and determine antibiotic sensitivity pattern Staphylococcus aureus from poultry meat and associated environment in and around Junagadh district area.

\section{Materials and Methods}

\section{Study area and Source of Material}

A total of 200 Poultry meat and associated environment samples which comprise of Tracheal swabs $(n=40)$, Cloacal swabs $(n=40)$, Skin swabs $(n=40)$, Meat $(n=40)$ and environment sample (knife samples $(n=20)$ and butcher's hand swabs $(\mathrm{n}=20)$ were collected from different retail poultry meat shops located in and around Junagadh district, under aseptic precautions. 
Isolation and identification of Staphylococcus aureus

Enrichment of samples was carried out in Peptone Water (PW) enrichment broth. 25 gm poultry meat and swab samples were homogenized with $90 \mathrm{ml}$ sterile enrichment broth peptone water and enriched for $24 \mathrm{hrs}$ at $37^{\circ} \mathrm{C}$. A loopful of inoculum from enrichment broth were streaked on Baird-Parker agar (BPA) medium supplemented with egg-yolk tellurite emulsion and incubated for $48 \mathrm{~h}$ at 37 ${ }^{\circ} \mathrm{C}$. Characteristic appearance of jet black colonies surrounded by a white halo zone on BPA (Fig. 1) and golden yellow colour on Nutrient Agar (Fig. 2) was considered as positive.

\section{Biochemical Characterization}

Suspected colony on BPA and Nutrient Agar was further characterized by gram's stain other biochemical tests like Catalase test, Oxidase test, Voges Proskauer test, Coagulase production, Deoxyribonuclease (DNase) activity.

\section{Determination of antibiotic susceptibility test (ABST) by Disc Diffusion method}

All the $S$. aureus isolates were tested for antibiotic susceptibility by the Kirby- Bauer disc diffusion method on Mueller Hinton agar using commercially used antibiotic discs.

\section{Results and Discussion}

The surveillance of food for microbial contamination is important for protection of public health and consumer interest. Now in this competitive global market era the production of safe food is mandatory. With this regard the general hygiene of poultry meat and their associate environment including personal hygiene of workers is also important.
Out of Two hundred (200) samples of poultry meat and associated environment samples obtained from in and around Junagadh district, $27(13.5 \%)$ isolate of $S$. aureus were isolated from the samples. The organisms that were isolated in the present study were important food borne pathogens in humans, and cause diseases in domestic animals.

In present study overall prevalence of $S$. aureus was found to be $13.5 \%$. According to sample wise study, the highest prevalence of $S$. aureus was detected from skin swabs (15.0\%) followed by meat samples $(12.0 \%)$, cloacal swabs $(10.0 \%)$ and tracheal swabs (7.50\%). From poultry meat associated environment samples, Butchers' hand swab show (25.0\%) and Knife swab (20.0\%) prevalence (Table 1).

In present study, over all prevalence of $S$. aureus $27(13.5 \%)$ detected which was correlate with findings of Hannig et al., (2012) who reported $11.2 \%(25 / 222)$ of $S$. aureus isolates from whole poultry carcass in Northwest Arkansas. The present findings were lower than $18.18 \%, 24.50 \%, 22.00 \%$, $30.10 \%$ reported by Akbar and Anal (2013), Onaolapo et al., (2017), Gwida and El-Gohary (2015) and Fan et al., (2015) respectively. However, the present finding is higher than the finding of Osman et al., (2015) and EIJakee et al., (2008) who observed $6.00 \%$, $8.00 \%$ prevalence respectively. The variation in the prevalence of $S$. aureus may be due to number of samples screen, sampling procedure, quality of water used for processing, improper sanitization of working surface as well as hygienic outlet in different shop in different country or any region.

The prevalence of $S$. aureus form Butchers' hand swabs $25.00 \%$ was in contrast with the finding of Gwida and El-Gohary (2015) who reported $40.0 \%$ of $S$. aureus colonize the skin 
of the chicken handlers. Similarly, Fan et al., (2015) also investigated the prevalence of $S$. aureus from human, meat and poultry origin in Henan Province in China. They reported that 54.8\% (34/62) human samples (nasal swabs, blood and fester) were positive for $S$. aureus which was in contrast to the present study finding. However, Contrary to the findings of our study, higher prevalence have been reported by Omololu and Bamidele, (2017) in Nigeria (62.5\%), Herve and Kumar, (2017) in Punjab (46.41\%), Moustafa et al., (2016) in Egypt (41.8\%). The variation in the present study is may be due to increase in the samples size of poultry meat sample and improper handling of poultry meat by their worker or poor personal hygiene prevalent in the retail shop.

\section{Antibiotic Sensitivity}

In the present study, S. aureus isolates were found variably resistant to the antibiotics tested. Most of the $S$. aureus isolates were showing high resistant activity towards Ampicillin (70.37\%) followed by Tetracycline (62.96\%), Co-Trimoxazole (33.33\%), Methicillin (25.92\%), Chloramphenicol $(22.22 \%)$ and Vancomycin (18.51\%) (Table 2 and Chart 1).

Table.1 Isolation of Staphylococcus aureus from poultry and associated environment

\begin{tabular}{|c|c|c|c|c|}
\hline \multicolumn{2}{|c|}{ Type of Sample } & $\begin{array}{c}\text { No of samples } \\
\text { examined }\end{array}$ & $\begin{array}{l}\text { Number of } \\
\text { samples } \\
\text { positive for } \\
\text { S. aureus }\end{array}$ & $\begin{array}{l}\text { Percentage of } \\
\text { S. aureus }(\%)\end{array}$ \\
\hline \multicolumn{2}{|c|}{ Tracheal swab } & 40 & 03 & 7.5 \\
\hline \multicolumn{2}{|c|}{ Skin swab } & 40 & 06 & 15.00 \\
\hline \multicolumn{2}{|c|}{ Cloacal swab } & 40 & 04 & 10.0 \\
\hline \multicolumn{2}{|c|}{ Meat } & 40 & 05 & 12.5 \\
\hline \multirow[t]{2}{*}{ Environment } & Knife swab & 20 & 04 & 20.00 \\
\hline & $\begin{array}{l}\text { Butchers'hand } \\
\text { swab }\end{array}$ & 20 & 05 & 25.00 \\
\hline \multicolumn{2}{|c|}{ Total } & 200 & 27 & 13.5 \\
\hline
\end{tabular}

Table.2 Antibiotic susceptibility of Staphylococcus aureus (N: 27) isolates to Antimicrobial agents

\begin{tabular}{|c|c|c|c|c|}
\hline $\begin{array}{c}\text { Sr. } \\
\text { No. }\end{array}$ & Name of the antibiotic & Sensitive & Intermediate & Resistant \\
\hline $\mathbf{1 .}$ & Ampicillin & $8(29.62 \%)$ & & $19(70.37 \%)$ \\
\hline 2. & Chloramphenicol & $21(77.77 \%)$ & - & $6(22.22 \%)$ \\
\hline 3. & Co-Trimoxazole & $18(66.66 \%)$ & - & $9(33.33 \%)$ \\
\hline $\mathbf{4 .}$ & Methicillin & $20(74.07 \%)$ & - & $7(25.92 \%)$ \\
\hline $\mathbf{5 .}$ & Tetracycline & $10(37.03 \%)$ & - & $17(62.96 \%)$ \\
\hline 6. & Vancomycin & $22(81.48 \%)$ & - & $5(18.51 \%)$ \\
\hline
\end{tabular}


Chart.1 Antibiotic susceptibility of Staphylococcus aureus (N: 27) isolates to antimicrobial agents

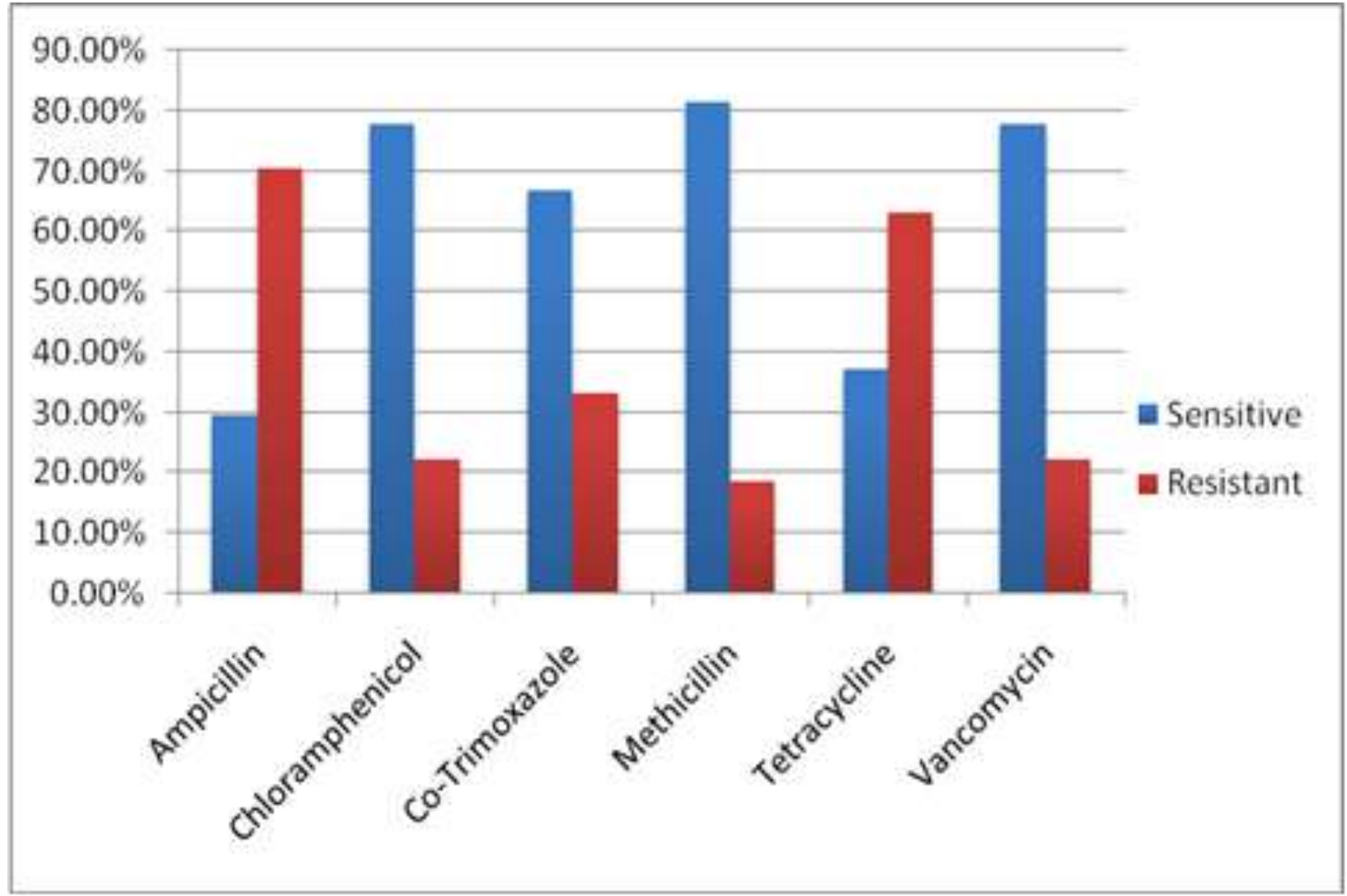

Fig.1 S. aureus on Baired parker agar having grey black colony

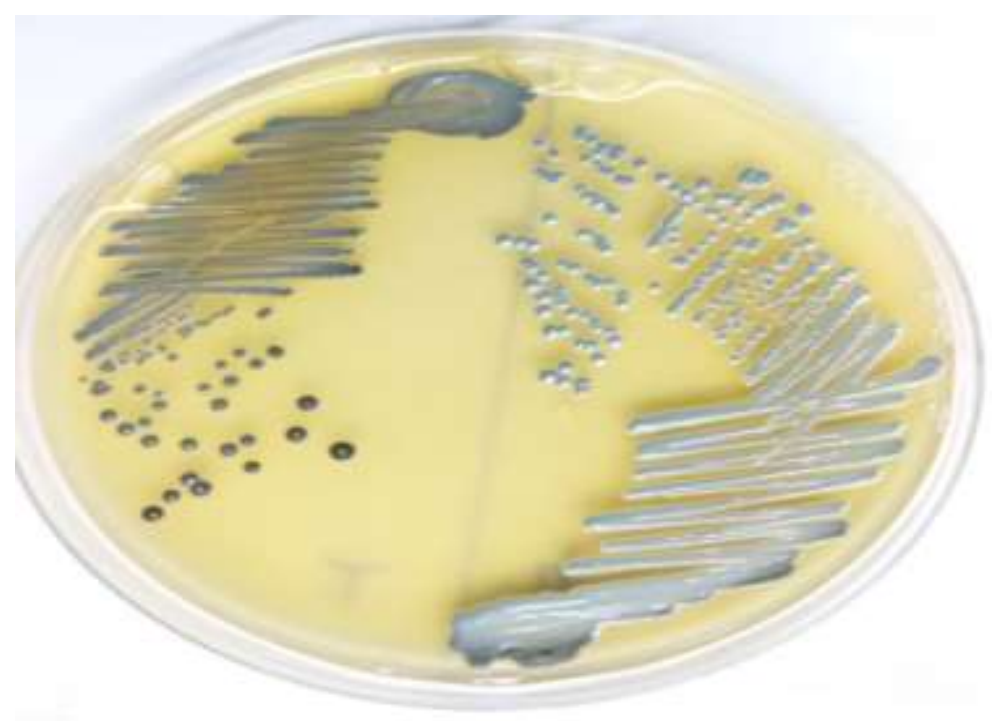


Fig.2 S. aureus on nutrient agar having golden color colony

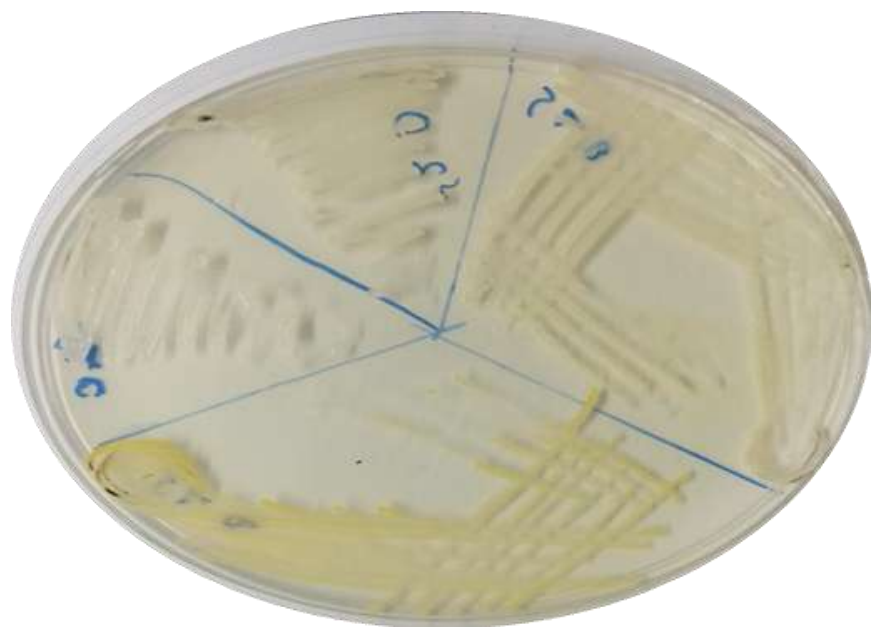

The high resistance of $S$. aureus isolates from fresh poultry meat to Ampicillin, Tetracycline and Co-Trimoxazole observed in this study was expected and however this report was not different from other studies reported by Similar patterns of antimicrobial susceptibility have been reported by Fan et al., (2015). The findings of Co-trimoxazole and Tetracycline in our study were somewhat similar with Onaolapo et al., (2017).

This might be due to extensive usage of these antimicrobial agents in animal husbandry over time period of time, which has contributed to the selection of drug resistant strains. In contrast to our study higher resistant to Ampicillin, Tetracycline and Vancomycin were reported by Abdalrahman et al., (2015). In present study the $S$. aureus strains were found highly resistant to ampicillin and tetracycline. It may be due to this drug are most commonly used in poultry. While comparing with other studies, differences in the antibiotic resistance may arise due to inappropriate use of antibiotics for each infection and the use of antibiotics as a growth factor in poultry feeding as growth promoter.

The majority of $S$. auresu isolates in our studied were found sensitive to Vancomycin, Chloramphenicol, Co-trimoxazole and
Methicillin. The results were in agreement with the findings of Ruban et al., (2018). However, higher sensitivity to Vancomycin, Chloramphenicol, Co-trimoxazole and Methicillin might be due to the fact that these antibiotics are rarely used in the poultry.

The Variations in sensitivity pattern of the isolates may be attributed to the use of different antibiotics in various countries for prophylaxis as well as growth promotion in poultry.

The present study reveals the fact that raw poultry meat from retail poultry shop is heavily contaminated with the prevalence of $S$. aureus. So, there is a need for educating the people on hygienic production of poultry meat in order to curb undesirable contamination of S. aureus.

The antibiotic resistance pattern of the bacterial isolates shows the high incidence of multi-drug resistant bacteria contaminants in poultry meat.

There may be transfer of bacteria from poultry to human being thereby causing gastrointestinal disorders and food borne illness which can be life threatening. So training should be given to meat handlers and 
butchers for hygienic production of meat and to minimize contamination of raw meat and meat products.

\section{References}

Abdalrahman, L. S., Wells, A. S. H. and Fakhr, M. K. (2015). Isolation, virulence, and antimicrobial resistance of Methicillin resistant Staphylococcus aureus (MRSA) and Methicillin sensitive Staphylococcus aureus (MSSA) strains from Oklahoma retail poultry meats. Int. J. Environ. Res. Public Health. 12: 6148-6161.

Akbar, A. and Anal, A. K. (2013). Prevalence and antibiogram study of Salmonella and Staphylococcus aureus in poultry meat. Asian Pac. J. Trop. Biomed. 3(2): 163-168.

Cunha, M. L. R. S., Peresi, E., Calsolari, R. A. O., Junior, J.P.A. (2006). Detection of enterotoxins genes in coagulasenegative Staphylococci isolated from food. Brazil J. Microbiol. 37:70-74.

EI-Jakee, J. E., Nagwa, A. S., Bakry, M., Zouelfakar, S. A., Elgabry, E. and Gad ESaid, W. A. (2008). Characteristics of Staphylococcus aureus strains isolated from human and animal sources. Am. Eurasian J. Agric. and Environ. Sci. 4(2): 221-229.

Fan, Y., Li, S. M., Deng, B. G and Zhao, Y. $X$. (2015). Prevalence and relevance analysis of multidrug-resistant Staphylococcus aureus of meat, poultry and human origin. Indian $J$. Anim. Res. 49(1): 86-90.

Gwida, M. and EI-Gohary, A. (2015). Prevalence and Characterization of Antibiotic Resistance Food Borne Pathogens Isolated from Locally Produced Chicken Raw Meat and their Handlers. J. Dairy, Vet. and Animal Res.. 3(1):1-7.

Hanning, I., Gilmore, D., Pendleton, S., Fleck,
S., Clement, A., Park, S. H., Scott, E. and Ricke, S. C. (2012). Characterization of Staphylococcus aureus isolates from retail chicken carcasses and pet workers in northwest Arkansas. J. Food Prot. 75(1):174178.

Herve, D. T. and Kumar, G. (2017). Prevalence of Staphylococcus aureus in Retail Chicken meat Samples in Jalandhar, Punjab. Research J. Pharm. and Tech. 10(1): 281-285.

Islam, N. N., Akter, M., Farzana, Z., Kader, A.J.B.N., Uddin, I., Siddiki, A.M.A.M. $\mathrm{Z}$ and Kamaruddin, K.M. (2014). Detection of Staphylococcus aureus in Frozen Chicken Rinse through Bacteriological and Nuc Gene Specific PCR Methods and their Drug Resistance Patterns in Southern Chittagong, Bangladesh. Research Journal of Microbiology, 9: 251-264.

Jackson, C.R., Davis, J.A. and Barrett, J. B. (2013). Prevalence and Characterization of MethicillinResistant Staphylococcus aureus Isolates from Retail Meat and Humans in Georgia. Journal of Clinical Microbiology. 51(4): 1199-1207.

Kearney, J., (2010). Food consumption trends and drivers. Philos. Trans. R. Soc. B:Biol.Sci., 365:2793-2807.

Świda, M. K., Chrobak-Chmiel,D., Rzewuska, M., Pławińska-Czarnak, J. and Binek, M. (2016). Characterisation of Staphylococcus aureus isolated from meat processing plants - a preliminary study. J Vet Res. 60: 441-446.

Moustafa, N.Y., Abd El-Hafiz, R.M. and ElBahy, E. F. (2016). Incidence of Staphylococcus aureus and Salmonella in Poultry Meat. Global Veterinaria 16 (6): 570-578

Omololu, J. and Bamidele, K.F. (2017). Antimicrobial Susceptibility Pattern of S. aureus and Salmonella sp isolated 
from Poultry Feed Sold in Ile Ife, Nigeria. Arch Clin Microbiol., 8(3):15.

Onaolapo, J. A., Igwe, J. C; Bolaji, R. O; Adeshina, G. O. and Parom, S. K.(2017). Antibiotics Susceptibility Profile of Staphylococcus aureus Isolated from Poultry Birds in Kaduna, Nigeria. $J \quad$ Clin Microbiol Antimicrob.1(1):1-6.

Osman, K. M., Amer, A. M., Badr, J. M. and Saad, A. S. A. (2015). Prevalence and antimicrobial resistance profile of Staphylococcus species in chicken and beef raw meat in Egypt. Foodborne. Pathog Dis. 12(5):406-413.

Owuna, G., Abimiku, R. H., Nkene I. H., Joseph G. W. and Ijalana, O. O. (2015). Isolation and Antibiotic Susceptibility of Staphylococcus aureus from Fresh Poultry Meat Sold in Keffi Metropolis, Nigeria. Int. J. Res. Stud. Biosci. 3(11):1-5.

Senait G. and Moorty, (2016). Isolation and Identification of Staphylococcus Species from Ready-To-Eat Meat
Products in and Around Debre-Zeit, Ethiopia. International Journal of Research in Agriculture and Forestry. 3(4):6-16.

Van der Vanter, T. (1999). Prospects for the future: Emerging problem of chemical /biological Conference of International Food Trade Beyond 2000: Science based Decision, equivalence and mutual Recognition Melbourne, Australia, Pp.11-15.

Ruban, W. S., Narendra Babu, R., Abraham, R. J. J., Senthilkumar, T.M.A., Kumaraswamy, P., Porteen, K. and Vemala, G. (2018). Prevalence and Antimicrobial Susceptibility of Staphylococcus aureus Isolated from Retail Chicken Meat in Chennai, India. Journal of Animal Research, 8(3): 423427.

World Health Organization (2015), Food safety, Fact sheet N 399. Available from:

http://www.who.int/mediacentre/factsh eets/fs399/en/.

\section{How to cite this article:}

Bhedi, K. R., S. H. Sindhi, J. B. Kathiriya, B. S. Mathapati and Bariya, A. R. 2019. Isolation and Antibiotics Susceptibility Profile of Staphylococcus aureus Isolated from Poultry Meat and Associated Environment in and around Junagadh District, Gujarat. Int.J.Curr.Microbiol.App.Sci. 8(10): 800-807. doi: https://doi.org/10.20546/ijcmas.2019.810.092 